\title{
Prolonged PR interval and coronary artery disease
}

\author{
H. B. Calleja and M. X. Guerrero \\ From Amerman Heart Clinic, Makati Medical Center, Makati, Philippines
}

Of 2744 patients seen in clinic practice, 37 were found to have a prolonged $P R$ interval. The causes of prolongation of the $P R$ interval were: congenital heart disease, 6; chronic rheumatic heart disease, 2; digitalis induced, 4; miscellaneous, 5; and coronary heart disease, 20. Of the 20 associated with coronary heart disease, $8(21 \cdot 6 \%$ of all the patients with prolonged PR interval) had myocardial infarction while $12(32 \cdot 4 \%$ of all the patients with prolonged PR interval) had angina pectoris. In those who had infarction, the location of the infarct was dominantly inferior.

The diagnostic possibilities of a prolonged $P R$ interval can be inferred from the high incidence of association with coronary heart disease. Thirty-two per cent of the total cases with prolongation of the PR interval in this study were due to coronary heart disease with angina, and of 193 cases of angina about $6 \cdot 2$ per cent had prolongation of the $P R$ interval.

The universally accepted electrocardiographic signs associated with cardiac pain are limited to abnormalities in the QRS, ST, and T wave, indicating either angina, coronary insufficiency, or acute myocardial infarction. Lesser known signs associated with cardiac pain are inversion of the $U$ wave mentioned by Wood (1956) and depression of the TU segment described by Evans and Pillay (1957).

In seemingly normal subjects, Averill and Lamb (1960) found a prolonged PR interval in only 5.2 per thousand compared to 8.6 for ST and T abnormalities. A similar study by Manning (1960) showed $T$ wave variations alone in 489 out of 17,000 fit, healthy young men or an incidence of 28.8 per thousand. The lower incidence of first-degree AV block in normal subjects underlines the diagnostic possibilities of this abnormality in patients with heart disease. Prolongation of the PR interval has not previously been associated with cardiac pain except as a conduction defect seen in acute myocardial infarction. In this paper we are introducing prolongation of the PR interval as an additional clue suggesting cardiac pain without myocardial infarction.

\section{Subjects and methods}

A total of 2744 electrocardiographic tracings representing

Received 5 July 1972.

1 This work was supported in part by the Kiwanis Heart Foundation, Inc., Quezon City; and the Amerman Heart Clinic, Makati Medical Center, Makati, Philippines and a Research Grant from Boehringer Ingelheim (Phil.), Inc. as many patients from the clinic files forms the material for this investigation. This number is the sum total of the initial electrocardiograms from patients seen in the clinic from 4 October 1960 to 3 I December 1970 inclusive. All patients had a basic study consisting of: fasting blood sugar, serum cholesterol, and a r2-lead electrocardiogram. A blood urea determination was also done in those patients who were hypertensive.

The PR interval was measured from the earliest inscription of the $P$ wave to the onset of the $Q R S$ complex in lead II. It was considered prolonged if it exceeded the upper limits of normal of $0.20 \mathrm{sec}$. In addition, the $12-$ lead electrocardiogram was scrutinized for additional signs of cardiac pain according to Evans and Pillay (1957). Other abnormalities, like left anterior hemiblock, left inferior hemiblock, QRS prolongation, ST-T changes, and effects of digitalis were carefully searched for.

The diagnosis of myocardial infarction was made from the generally accepted electrocardiographic signs and a rise in the cardiac enzymes. Acute myocardial infarction was diagnosed by the presence of a pathological $\mathrm{Q}$ wave accompanied by ST rises in the same leads and raised serum aspartate aminotransferase (SGOT) and/or lactic dehydrogenase (LDH). Myocardial infarction was considered old when pathological $Q$ waves were associated with normal cardiac enzymes and absence of acute or recent episode of cardiac pain.

A history of retrosternal or praecordial pain, pressure, heaviness, or tightness related to effort, with or without radiation to the neck or arms, was the only basis for the diagnosis of angina pectoris. The physical examination, laboratory tests, electrocardiogram, and chest $x$-rays were correlated with the clinical history. Coronary arteriographic studies were not available. 


\section{Results}

Of the 2744 electrocardiograms, 37 showed prolonged PR interval, an incidence of 13.5 per thousand. The clinic charts of these 37 electrocardiograms were reviewed. Accordingly, the different conditions associated with prolonged PR interval are listed in Table $I$. There were 6 patients who had congenital heart disease, 2 with rheumatic heart disease, and 5 with diverse clinical conditions. Four patients were receiving digitalis, and were grouped under the heading 'digitalis-induced'. One patient with typical angina was included in this group because a repeat electrocardiogram, after digitalis was discontinued, showed a normal PR interval.

Coronary heart disease associated with prolonged PR interval was found in 20 patients. Of these, 5 had electrocardiographic and enzymatic evidence of acute myocardial infarction. Inferior myocardial infarction was present in 6 and anterior myocardial infarction was found in only 2 . The 3 patients with old myocardial infarction ( 2 anterior, $I$ inferior) were receiving maintenance digitalis. The real cause of the PR prolongation in these 3 cases cannot be ascertained since digitalis could not be discontinued.

TABLE I Conditions associated with prolonged PR interval in 37 cases

Congenital heart disease

Chronic rheumatic heart disease

Digitalis induced

Miscellaneous

Coronary heart disease

a) with myocardial infarction inferior myocardial infarction 6 anterior myocardial infarction 2

b) with angina only

37
Finally, in 12 patients a prolonged PR interval accompanied the manifestation of angina in coronary heart disease. This represents 6.2 per cent of 193 with angina out of 2744 patients. None of them had had a previous myocardial infarction. The youngest was 44 years and the oldest was 72 years. There were 9 men and 3 women. The follow-up period from the initial electrocardiogram to the present ranged from $2 \frac{1}{2}$ years to Io years. The I2-lead electrocardiograms were scrutinized for additional abnormalities. Table 2 shows the associated electrocardiographic changes.

\section{Follow-up}

\section{Case 66-267}

A 67-year-old woman with prolonged PR interval (Fig. I) was seen in 1966 with cardiac pain. When next seen in 1969 she showed a complete AV block resulting from a bilateral bundle-branch block, type $\mathrm{Ib}$ of Lepeschkin (1964). The complete AV block tracing shows a right bundle-branch block with left inferior hemiblock.

\section{Case 68-235}

A 68-year-old man was followed for 3 years with no change in the PR interval and ST depression in I, II, aVL, V4-6 (Fig. 2).

\section{Case 70-288}

A 7I-year-old man, not included in the infarction group, showed notched $\mathrm{P}$ wave with prolonged $\mathrm{PR}$ interval of $0.24 \mathrm{sec}$ and generalized ST depression in I, II, aVL, $V_{5}-6$. He was admitted to the hospital in 1970 for amputation of the right leg because of diabetic gangrene. Two days after amputation he developed acute inferior and anteroseptal myocardial infarction and died (Fig. 3).

\section{Case 70-312}

A 6I-year-old man was admitted to the coronary care unit because of severe and prolonged retrosternal pain. The electrocardiogram showed signs of early acute inferior myocardial infarction. Subsequent serial tracings

TABLE 2 Prolonged PR interval and associated electrocardiographic abnormalities

\begin{tabular}{|c|c|c|c|c|c|}
\hline Case No. & Age $(y r)$ & $\operatorname{Sex}$ & Rate & $P R$ & Other electrocardiographic abnormalities \\
\hline $60-4$ & 44 & $\mathbf{F}$ & 60 & 0.24 & V5-6 sickle-shaped ST depression \\
\hline $60-5$ & 62 & $\mathbf{M}$ & 55 & 0.22 & Left anterior hemiblock \\
\hline $60-20$ & 71 & $\mathbf{M}$ & 65 & 0.26 & Incomplete right bundle-branch block; TU depression \\
\hline $64-145$ & 43 & $\mathbf{M}$ & 80 & 0.24 & Left anterior hemiblock; QRS - 0.14 sec \\
\hline $66-267$ & 67 & $\mathbf{F}$ & 60 & 0.24 & $\mathrm{~T}$ in lead I low: V5-6 sickle-shaped ST depression \\
\hline $68-235$ & 68 & $\mathbf{M}$ & 66 & 0.24 & ST depression in I, II, aVL, $\mathrm{V}_{4-6}$ \\
\hline $68-270$ & 72 & $\mathbf{M}$ & 55 & 0.26 & $\mathrm{~T}$ in lead I low: $\mathrm{V}_{5-6}$ sickle-shaped ST depression \\
\hline $69-56$ & 58 & $\mathbf{F}$ & 60 & 0.24 & Inferior axis deviation \\
\hline $69-254$ & 62 & $\mathbf{M}$ & 75 & 0.24 & V5-6 plane ST depression; TU depression \\
\hline $69-260$ & 54 & $\mathbf{M}$ & 60 & 0.24 & V5-6 sickle-shaped ST depression; TU depression \\
\hline $70-288$ & 71 & $\mathbf{M}$ & 75 & 0.24 & Notched $\mathrm{P}$ wave; ST depression in I, II, aVL, V5-6 \\
\hline $70-312$ & 61 & $\mathbf{M}$ & 65 & 0.26 & $\mathrm{~T}$ in $\mathrm{V}_{2}-6$ inverted \\
\hline
\end{tabular}



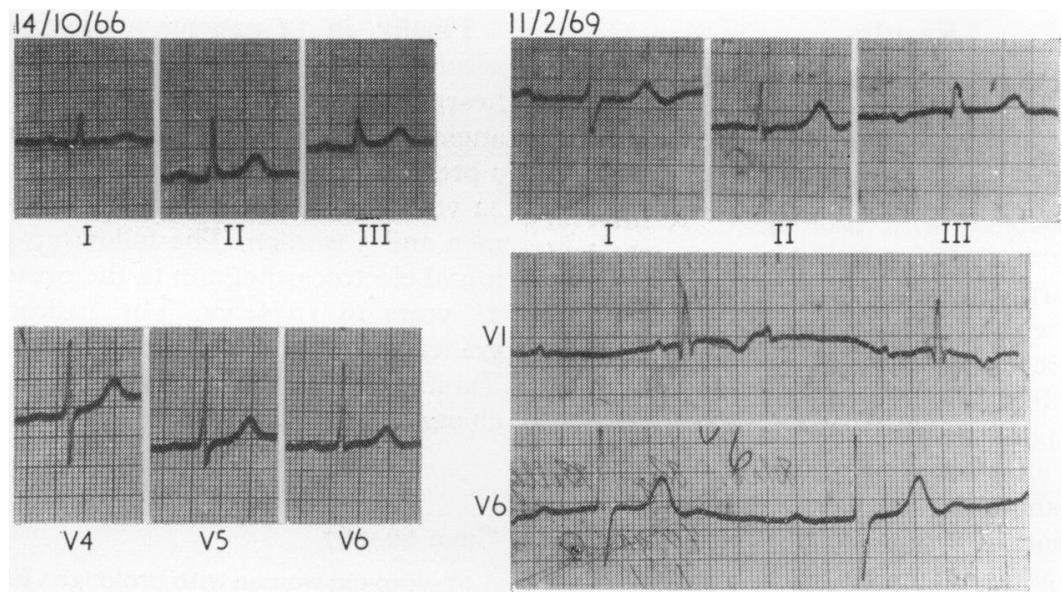

FIG. I Tracing on 14 October 1966 shows normal sinus rhythm with prolonged PR interval. The electrocardiogram on II February 1969 shows complete AV block with bilateral bundlebranch block (right bundle-branch block and left inferior hemiblock).
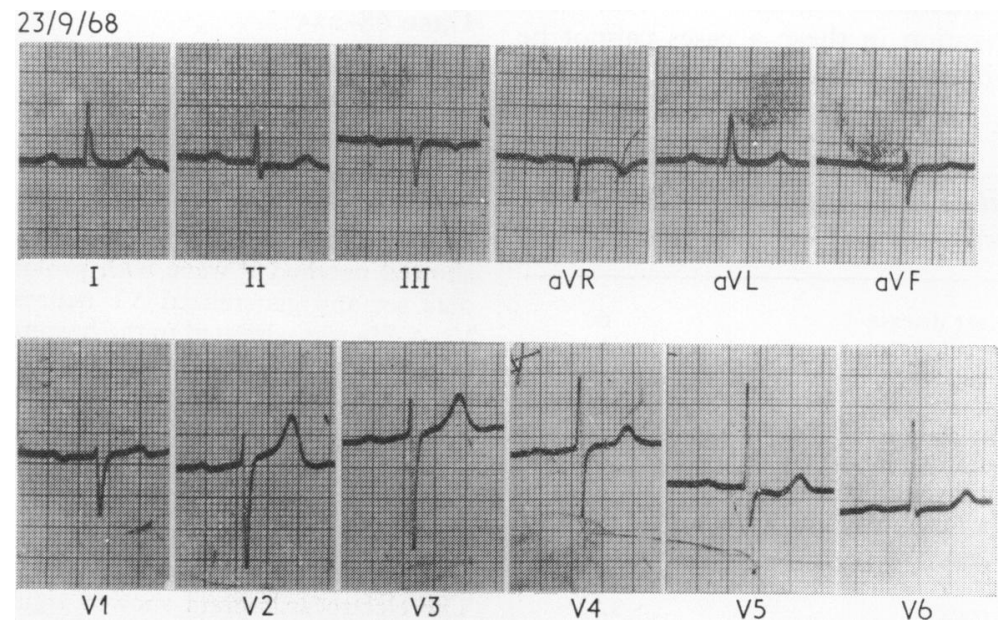

FIG. 2 The PR interval is prolonged with ST-T changes in $I, I I, a V L, V 4-6$. The electrocardiogram has remained essentially the same for the past 3 years.

failed to show evolutionary changes of myocardial infarction and the SGOT and LDH remained normal. However, 2 weeks later an electrocardiogram was taken during an attack of angina revealing a prolonged PR interval (Fig. 4).

\section{Discussion}

The incidence of prolonged PR interval in this investigation is understandably higher than in the reports of Averill and Lamb (1960) and Manning (1960). Our 2744 cases represent patients seen in the clinic, about 75 per cent of whom are 30 years old or over. The age range spreads from I year to 86 years. Table 3 shows the incidence of prolonged PR interval in apparently healthy air-force trainees and in our series. According to James (197I), the AV node gets its blood supply from the right coronary artery in 90 per cent and from the left circumflex in Io per cent of cases. Evidence from this study shows that of the 8 patients with myocardial infarction, 6 had inferior myocardial infarction. An additional patient died of acute inferior and anteroseptal myocardial infarction and another showed electrocardiographic changes consistent with acute inferior 

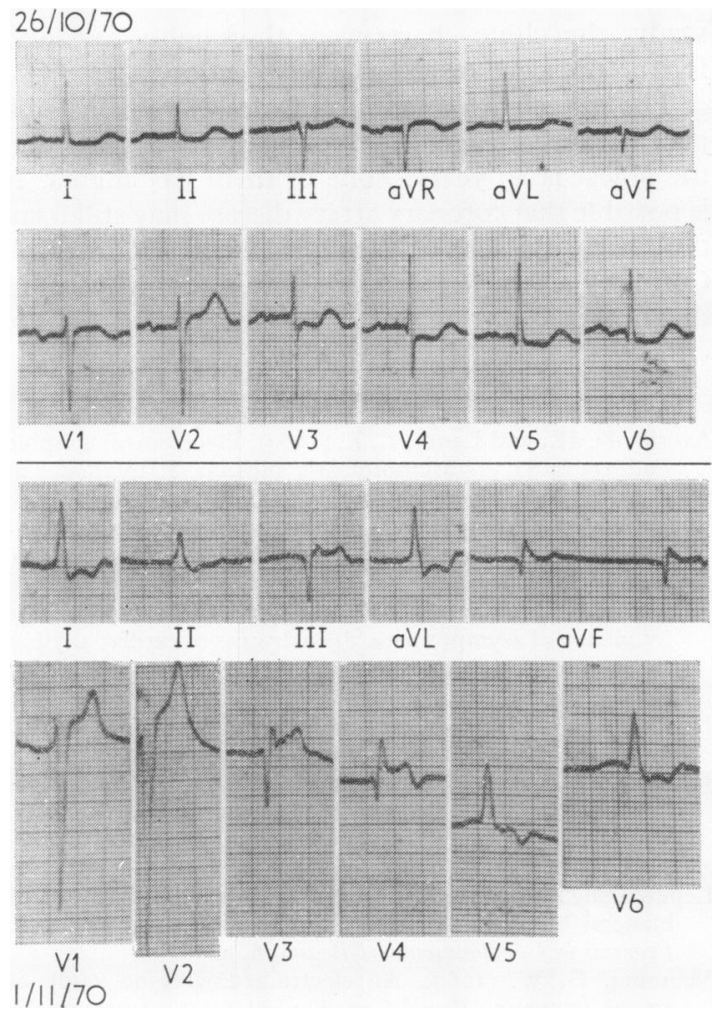

FIG. 3 The upper tracing on 26 October 1970 shows notched $P$ waves with prolonged $P R$ interval and $S T-T$ changes in leads I, II, aVL, V4-6. The lower tracing shows acute inferior and anteroseptal myocardial infarction. The patient died shortly after this tracing was taken.

TABLE 3 Incidence of first-degree $A V$ block

\begin{tabular}{lrrrr}
\hline Series & Total & $\begin{array}{l}\text { Age } \\
\text { range }\end{array}$ & $\begin{array}{l}\text { First- } \\
\text { degree } \\
\text { block }\end{array}$ & $\begin{array}{l}\text { Incidence } \\
\text { per } \\
\text { thousand }\end{array}$ \\
\hline $\begin{array}{l}\text { Manning (1960) } \\
\text { Averill and }\end{array}$ & 17,000 & $13-24$ & 76 & $4 \cdot 5$ \\
$\begin{array}{l}\text { Lamb (1960) } \\
\text { Present series }\end{array}$ & $\begin{array}{r}67,375 \\
2,744\end{array}$ & $\begin{array}{rr}17-54 \\
1-86\end{array}$ & $\begin{array}{r}350 \\
37\end{array}$ & $\begin{array}{r}5.2 \\
13.5\end{array}$ \\
\hline
\end{tabular}

myocardial infarction. It appears that an inferior myocardial infarction can be anticipated in patients with prolonged PR interval. Further observation is necessary.

Patients with angina showed no special marks regarding the location, character, and occurrence of pain. Likewise, the history, physical, and laboratory findings were no different from the average patient with typical anginal pain. The electrocardiographic changes showed constant abnormalities in their follow-up tracings. All patients have more than 2 years follow-up with at least 2 electrocardiograms. The PR interval prolongation was stable, except in one patient in whom this abnormality was present only during an anginal attack.

All electrocardiograms were taken with the patient in the supine position. There was no attempt to shorten the PR interval by various methods, since none of them can reliably differentiate the pathological from the physiological (Johnson, Averill, and Lamb, 1960). The ventricular rate did not seem to influence the PR interval. There were as many patients with ventricular rates below 60 beats a minute as those above.

Only one patient had a PR interval as long as 0.28 sec. In another 3 the PR interval was 0.26 sec, 2 of whom were in their 70's, being 71 and 72 years; while the other, aged 6I, had his tracing taken during an attack of angina. In general, all were above 50 years except 2 who were in their fourth decade. In contrast, Hinkle, Carver, and Stevens (1969) failed to observe first-degree AV block in 283 continuous 6-hour electrocardiographic recordings of 301 asymptomatic middle-aged men.

All patients had additional electrocardiographic abnormalities. Two had left anterior hemiblock.
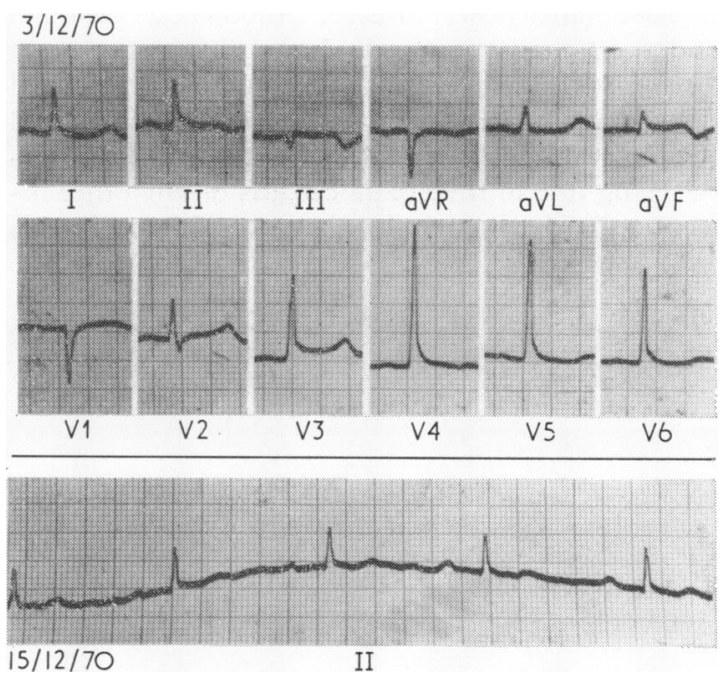

FIG. 4 The upper tracing suggests acute inferior myocardial infarction. Serial tracings however failed to show evolutionary changes and serial SGOT and LDH remained normal. Lower tracing of lead II taken during angina shows prolonged $P R$ interval. 
Sickle-shaped ST depression in $\mathrm{V}_{5}-6$ was present in 4; plane $S T$ depression in $\mathrm{V}_{5}-6$ in $\mathrm{I}$; and $\mathrm{TU}$ depression in $V_{5}-6$ in 3. Generalized ST depression was found in 2 patients while $T$ in V2-6 was inverted in $I$. The $Q R S$ complex was prolonged to $0.14 \mathrm{sec}$ in $\mathrm{I}$ and in another incomplete right bundlebranch block was present. The presence of these electrocardiographic abnormalities, which are already known signs associated with cardiac pain, strengthens the reliability of prolongation of the $P R$ interval as an additional sign.

The high incidence of coronary heart disease as a cause of PR prolongation in this series (20 out of 37 or 54 per cent) indicates its importance in diagnosis. If congenital heart disease and digitalis are removed from the list of causes, the only large group remaining is that due to coronary heart disease with or without infarction. Considering that the age range of this series is from I year to 86 years, the occurrence of prolonged PR interval almost exclusively in the older age group (3I out of 37 ) is doubly significant. In fact, 83.8 per cent belonged to ages 28 years and above. A recent report by Page et al. (1970) shows that age alone can reliably predict the occurrence of coronary heart disease. Incidence of coronary heart disease changes from 12 per cent at age 28 years to 84 per cent at 70 years.

It is interesting to note that while rheumatic carditis is a leading cause of heart disease in our country, prolonged PR interval is not common in our experience. In this series only 2 are possibly related to rheumatic heart disease. Another 2 included under 'digitalis induced' have rheumatic heart disease with atrial fibrillation converted to normal sinus rhythm producing in the process prolonged $P R$ interval. The possibility of prolonged PR interval being due to rheumatic carditis or any other infection for that matter has been considered in this study; the clinic charts were thoroughly reviewed for the presence or absence of infection.

The miscellaneous group of 5 cases remains suspect because of age. The youngest is 37 years and the oldest is 49 years: none of them has angina. It is possible that coronary artery disease may still form the main substrate of their prolonged PR interval. Coronary cinearteriography should be helpful in these cases.

\section{References}

Averill, K. H., and Lamb, L. E. (1960). Electrocardiographic findings in 67,375 asymptomatic subjects. I. Incidence of abnormalities. American fournal of Cardiology, 6, 76.

Evans, W., and Pillay, R. K. (1957). Additional electrocardiographic signs of cardiac pain. British Heart fournal, 19, 366.

Hinkle, L. E., Jr., Carver, S. T., and Stevens, M. (1969). The frequency of asymptomatic disturbances of cardiac rhythm and conduction in middle-aged men. American fournal of Cardiology, 24, 629.

James, T. N. (197I). Coronary circulation in acute myocardial infarction. British Heart fournal, 33, Suppl. 138.

Johnson, R. L., Averill, K. H., and Lamb, L. E. (I960). Electrocardiographic findings in 67,375 asymptomatic subjects. VII. Atrioventricular block. American fournal of Cardiology, 6, 153.

Lepeschkin, E. (1964). The electrocardiographic diagnosis of bilateral bundle branch block in relation to heart block. Progress in Cardiovascular Diseases, 6, 445.

Manning, G. W. (1960). An electrocardiographic study of 17,000 fit, young Royal Canadian air force aircrew applicants. American fournal of Cardiology, 6, 70.

Page, I. H., Berretoni, J. N., Butkus, A., and Sones, F. M., Jr. (1970). Prediction of coronary heart disease based on clinical suspicion, age, total cholesterol, and triglyceride. Circulation, 42, 625.

Wood, P. (1956). Diseases of the Heart and Circulation, 2nd ed. J. B. Lippincott, Philadelphia.

Requests for reprints to Dr. H. B. Calleja, Amerman Heart Clinic, Suite 327, Makati Medical Center, Makati, Philippines. 